\title{
Engineering of super bactericidal cotton using pyridinium/di-N-chloramine siloxane with intensified synergism
}

Yong Chen ( $\nabla$ ychen168@126.com )

Shandong University of Science and Technology https://orcid.org/0000-0003-4915-8389

\section{Yuyu Wang}

Shandong University of Science and Technology

\section{Zhendong Wang}

Shandong University of Science and Technology

Qiang Zhang

Shandong University of Science and Technology

Qiuxia Han

Shandong University of Science and Technology

\section{Research Article}

Keywords: pyridinium/di-N-chloramine, intensified synergism, cotton, bactericidal surface

Posted Date: March 1st, 2021

DOl: https://doi.org/10.21203/rs.3.rs-218115/v1

License: (9) This work is licensed under a Creative Commons Attribution 4.0 International License. Read Full License 
1 Engineering of super bactericidal cotton using pyridinium/di- $N$-chloramine

2

\section{siloxane with intensified synergism}

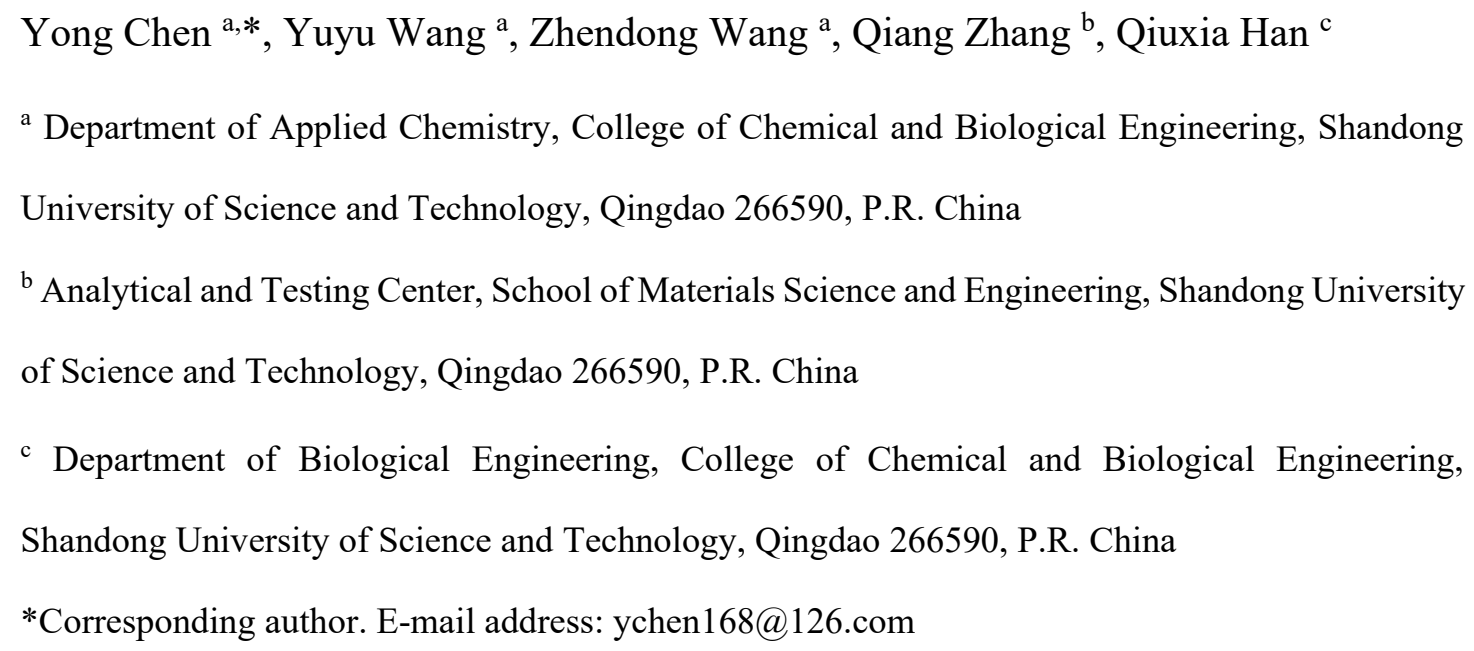

Abstract Tuning the ratio of complementary biocidal groups in a composite unit is proved to be a tactic to better minimize their weaknesses to realize higher synergism. A silane monomer, 6-(pyridin-4-yl)-3-(3-(trimethoxysilyl)propyl)-1,3,5-triazinane-2,4dione, with biocidal precursors of one pyridinium and two $\mathrm{N}$-chloramine sites was synthesized, hydrolyzed and dehydrocondensed on cotton cellulose. Specially, isonicotinaldehyde was ammonolyzed with biuret to produce 6-(pyridin-4-yl)-1,3,5triazinane-2,4-dione that subsequently reacted with ( $\gamma$-chloropropyl)trimethoxysilane to synthesize the silane monomer through nucleophilic substitution. The modifier on cotton was quaternized and chlorinated to transform the one pyridine and two amide $\mathrm{N}-\mathrm{H}$ structures in each unit of the silicone to pyridinium and $\mathrm{N}$-chloramine counterparts. The cationic pyridinium increases the hydrophilicity of the unit and electrically draws anionic bacteria to its two adjacent highly fatal $N$-chloramine sites, achieving a faster contact-killing rate than not only monofunctionality but also basic synergistic 
integration of one cationic center and one $\mathrm{N}$-chloramine. This phenomenon is therefore referred to as "intensified synergism" and provides crucial information for the design of more powerful biocides. The pyridinium/di- $N$-chloramine silicone coating exhibited extraordinary durability towards UV irradiation, washing cycles and long-term storage due to the good UV resistance and chemical inertness of pyridinium and silicone backbone.

\section{Graphical Abstract}

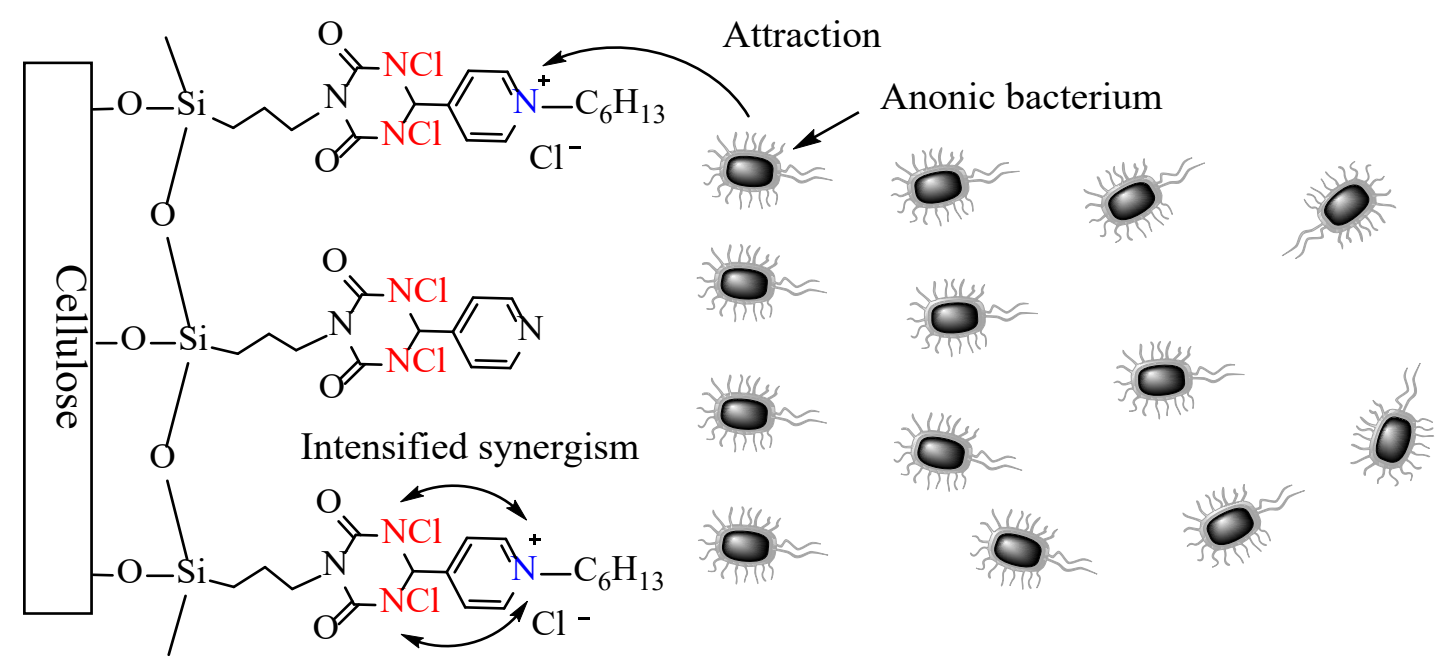

Keywords: pyridinium/di- $N$-chloramine; intensified synergism; cotton; bactericidal surface

\section{Introduction}

The fight against bacterial infection has run through the history of mankind. Despite the great improvement of the sanitary conditions, bacterial contamination still causes loss of billions of dollars worldwide every year (Ding X et al., 2018). Antibacterial modification of material surfaces is one of the most commonly used strategies for contamination control. Wherein, the modification of cotton has attracted particular 
attention owning to its wide usage in daily life and hygiene field while the hydrophilicity resulting from surface hydroxyl groups facilitates the growth and reproduction of pathogenic microorganisms (Cerkez I et al., 2011; Ren X et al., 2009). Therefore, the development of biocidal coating on cotton for better performance than reported ones is still highly desirable.

Attachment of biocides to cotton needs a friendly and efficient modification method that can be cataloged as a physical or chemical one. Physical methods such as layer-by-layer assembly (Cerkez I et al., 2011; Gomes A P et al., 2015) and interpenetration in supercritical fluid (Chen Y et al., 2013) have been applied to the formation of biocidal coatings. The application of physical methods is not the mainstream solution because layer-by-layer assembly works well on highly charged substrates while cotton is only slightly charged and impenetration in supercritical fluid needs high pressure vessels that are usually expensive and hard to operate. In contrast, cotton is usually modified by chemical methods since it has surface reactive hydroxyl groups. However, the areal density of hydroxyl group of cotton is relatively low so that potent biocidability cannot be achieved when each hydroxyl group only bonds with one biocidal functionality. The problem is often addressed using two strategies. One is the generation of free radicals on cotton for initialization of polymerization of biocidal monomers to compensate the sparse hydroxyl sites (Luo G et al., 2017; Luo J and Y Sun, 2006; Ma W et al., 2015). The second and most used one is the employment of silanes as carriers of biocidal groups since each of their hydrolyzates has three silanol groups that can condense with both counterparts in other hydrolyzates and hydroxyl 
groups on surface of cotton to form crosslinked polymeric silicone coatings (Chen Y et al., 2020; Kou L et al., 2009; Ren X et al., 2008).

Cotton was initially decorated with single functionality including $N$-halamines $(N$ chloramines and $\mathrm{N}$-bromamines) (Cheng X et al., 2015; Luo G et al., 2017; Zhang S et al., 2019), antibiotics (Liu X Y et al., 2019; Qu W et al., 2019), metals and metal oxides (El-Rafie M et al., 2014; Ibrahim M M et al., 2019; Xu Q et al., 2018), and cationic salts (quaternary ammonia salts and pyridinium ions, etc.) (Przybylak $\mathrm{M}$ et al., 2018; Zhang S et al., 2018b). $N$-halamines and cationic salts have stood out due to their low cost, broad-spectrum efficacy, and abound types. However, the use of single biocidal group has inherent disadvantage since bacteria have a vast diversity of structures and hence it is hard for one functionality to possess all of desired properties (Ates B and I Cerkez, 2017). For example, cationic salts kill bacteria through penetration into the anionic cytoplasmic membranes and hence are not efficient in eliminating Gramnegative bacteria that have thick cellular walls (Liang $\mathrm{J}$ et al., 2006). $N$-halamines are relatively hydrophobic and cannot sufficiently contact with bacterial suspension so that a higher concentration sometimes does not lead to a faster killing (Ren X et al., 2009). Moreover, $N$-halamines are consumed during the killing process and the substrate gradually loses biocidability before regeneration.

To address the disadvantage of single functionality, combination of different types of functionalities is used as a tactic to diminish the drawbacks of each of them. For instance, silver was integrated with cationic polymers for modification of cotton (Chen X et al., 2015) and PET (Zhang S et al., 2018a) for better performance. Since cationic 
salts and $N$-halamines have complementary properties, their combination is hypothesized to have good synergism. In such a composite unit, the cationic salt can increase the hydrophilicity to address the hydrophobicity of $N$-halamine, electronically attract anionic bacteria to $\mathrm{N}$-halamine, and provide certain biocidability when $\mathrm{N}$ halamine sites are consumed entirely (Kang Z-Z et al., 2013; Li L et al., 2012; Liu Y et al., 2013). That is, although cationic salt is a mild biocidal group yet it can facilitate the contact of the highly lethal $N$-halamine with bacteria to achieve a faster killing compared with any functionality alone. Furthermore, since the biocidal ability of cationic salt is auxiliary and the main contributor of biocidability is $N$-halamine, we further hypothesized that the combination of one cationic center and multiple $\mathrm{N}$ halamines can realize even higher antibacterial efficacy (referred to as intensified synergism) than the counterpart of one cationic center and one $N$-halamine (basic synergistic format).

Besides the combination, several other important principles should be beared in mind when designing a composite unit with not only promising biocidability but also other desirable properties. Firstly, it is desirable that the composite unit is polymerizable since polymers do not penetrate into human skins, have longer life yet lower toxicity (Krishnan S et al., 2006). The second rule is that the cyclic $N$-halamines are preferred since they are more stable than the acyclic counterparts (Dong A et al., 2010; Liang J et al., 2007). Moreover, it is beneficial to conjugate $N$-halamine with hydrophobic neighbors to address its hydrophilicity (Kou L et al., 2009; Ren X et al., 2009). 
A composite unit of one cationic center and several cyclic $N$-halamines with hydrophilic neighbors is then assumed to have better overall properties than current ones. To test the hypothesis, a silane with a composite unit that bears biocidal precursors of a cationic pyridinium and two amide $N$-chloramine sites in a hydrophilic 6membered ring was design and synthesized herein as shown in Scheme 1. Isonicotinaldehyde was firstly reacted with biuret to produce 6-(pyridin-4-yl)-1,3,5triazinane-2,4-dione that was reacted with ( $\gamma$-chloropropyl)trimethoxysilane (CPTMO) to synthesize the silane named 6-(pyridin-4-yl)-3-(3-(trimethoxysilyl)propyl)-1,3,5triazinane-2,4-dione via base-catalyzed nucleophilic substitution. Such a silane meets all of the previously discussed requirements. This is because its pyridine and two amide hydrogens can be converted to complementary pyridinium and amide $N$-chloramines to satisfy the requirements of intensified synergism due to the combination of one cationic center and two $\mathrm{N}$-chloramines, hydrophilicity due to the water soluble pyridinium and the 6-membered ring, stability due to the cyclic $N$-chloramine structure. Finally, the saline is polymerizable after hydrolysis via dehydration condensation to fulfill the requirement of the formation a polymeric biocidal layer on cotton. The studies herein proved the assumed virtues of such combination.

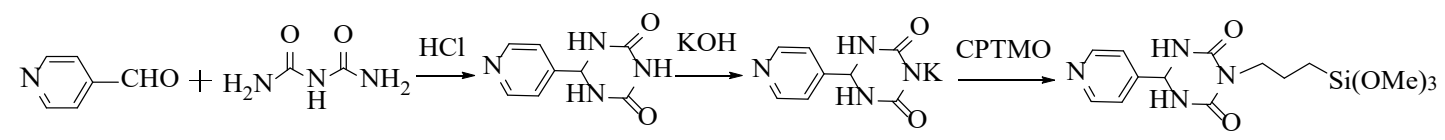

Scheme 1. Synthesis of 6-(pyridin-4-yl)-3-(3-(trimethoxysilyl)propyl)-1,3,5-triazinane-2,4-dione 


\section{Experimental}

Materials

Biuret was purchased from Nine Ding Chemistry (Shanghai) Co., Ltd. Isonicotinaldehyde was obtained from Shanghai Macklin Biochemical Co., Ltd. $\mathrm{HCl}$ (36\%) was supplied by Yantai Far Eastern Fine Chemical Co., Ltd. KOH and anhydrous ethanol were provided by Chengdu Kelong Chemical Co., Ltd. Aqueous $\mathrm{NaClO}(10 \%)$ was purchased from Tianjin Guangfu Fine Chemical Co., Ltd. $\mathrm{Na}_{2} \mathrm{CO}_{3}$ was supplied by Tianjin Bodi Chemical Industry Co., Ltd. ( $\gamma$-Chloropropyl)trimethoxysilane was purchased from Shandong West Asia Chemical Co., Ltd. 1-Chlorohexane was purchased from Sinopharm Chemical Reagent Co., Ltd. KI was purchased from Tianjin Jinbei Fine Chemical Co., Ltd. Cotton swatches were purchased from Dongguan Yunfan Textile Co., Ltd. Escherichia coli and Staphylococcus aureus were purchased from Guangdong Institute of Microbiology. All other chemicals were obtained from Shanghai Macklin Biochemical Co., Ltd.

\section{Characterization}

Infrared spectrum of each produce was illustrated by a Thermo Nicolet Magna IR-560 spectrometer using transmission technique ( $\mathrm{KBr}$ pellet). The spectra were collected at $0.5 \mathrm{~cm}^{-1}$ resolution and 8 scans in the $400 \sim 4000 \mathrm{~cm}^{-1}$ wavenumber range.

Cotton fibers were vacuum-coated with platinum using a 108auto sputtering coater (Cressington scientific instruments Ltd.) and then characterized with a FEI Nano SEM450 field emission scanning electron microscope (SEM) at an accelerating voltage 
of $15 \mathrm{kV}$ under a chamber pressure of $1 \times 10^{-4} \mathrm{~Pa}$ to analyze the morphology of the biocidal coating.

X-ray photoelectron spectroscopy (XPS) spectra of samples were detected with a Thermo Scientific Escalab 250Xi spectrometer installed with an Al Ka monochromatic X-ray source. Spectral acquisitions were performed under a chamber pressure of $1 \times 10^{-6}$ $\mathrm{Pa}$ at a test angle of $45^{\circ}$. Wide scan $(1$ to $1000 \mathrm{eV})$ were acquired at an analyzer pass energy of $100 \mathrm{eV}$ and a resolution of $1 \mathrm{eV}$ while high resolution scans were recorded at an analyzer pass energy of $23.5 \mathrm{eV}$ and a resolution of $0.05 \mathrm{eV}$. Binding energy (BE) of aliphatic carbon $\left(\mathrm{C}_{1 \mathrm{~s}}\right)$ was set to $284.6 \mathrm{eV}$ for calibration of charging effects. Preparation of 6-(pyridin-4-yl)-3-(3-(trimethoxysilyl)propyl)-1,3,5-triazinane-2,4dione

$1.55 \mathrm{~g}$ of biuret (15 mmol), $1.61 \mathrm{~g}$ of isonicotinaldehyde (15 mmol), and $16.73 \mathrm{~g}$ of $36 \%$ $\mathrm{HCl}(16.5 \mathrm{mmol})$ were mixed in a $50 \mathrm{~mL}$ flask at room temperature and stirred for 24 h. The product of 6-(pyridin-4-yl)-1,3,5-triazinane-2,4-dione was then precipitated out and collected with filtration after using $\mathrm{Na}_{2} \mathrm{CO}_{3}$ to neutralize the reactant mixture.

$3.84 \mathrm{~g}$ of 6-(pyridin-4-yl)-1,3,5-triazinane-2,4-dione (20 mmol) was transformed into a potassium salt by refluxing with $1.12 \mathrm{~g}$ of $\mathrm{KOH}(20 \mathrm{mmol})$ in $30 \mathrm{~mL}$ ethanol for $20 \mathrm{~min} .3 .97 \mathrm{~g}$ of ( $\gamma$-chloropropyl)trimethoxysilane $(20 \mathrm{mmol})$ was then added into the mixture and refluxed for $3 \mathrm{~h}$ to complete the nucleophilic substitution of chlorine in $(\gamma$ chloropropyl)trimethoxysilane with nitrogen anion in potassium salt using $0.1 \mathrm{~g}$ of KI as catalyst. 
Biocidal modification of cotton fibers (Scheme 2)

The $\mathrm{pH}$ value of the above solution was adjusted to $\sim 5$ with $\mathrm{CH}_{3} \mathrm{COOH}$. The methoxysilyl groups originating from ( $\gamma$-chloropropyl)trimethoxysilane were hydrolyzed for $20 \mathrm{~min}$ in this solution to silanol groups. Cotton swatches were immersed into the hydrolysis solution for $15 \mathrm{~min}$. The immersed swatches were taken out and cured at $100^{\circ} \mathrm{C}$ in a vacuum oven for $1 \mathrm{~h}$ to complete the dehydrocondensation.

The swatches were then washed in an ultrasonic oscillator to remove physically adsorbed impurities and dried in the air.

The as-prepared swatches were refluxed in solution of $2 \mathrm{~mL}$ 1-chlorohexane and $20 \mathrm{~mL}$ ethanol for $6 \mathrm{~h}$ to quaternize the pyridine rings to pyridinium ions. The quaternized swatches were dried in the air and then chlorinated with $10 \% \mathrm{NaClO}$ solution for $6 \mathrm{~h}$ at the room temperature to convert the $\mathrm{N}-\mathrm{H}$ bonds to $\mathrm{N}-\mathrm{Cl}$ formats. The chlorinated fibers were then rinsed with distilled water to remove free chlorine and dried at ambient temperature. Each unit of the silicone coating has one pyridinium and two $N$-chloramine sites in the best situation and the then final sample was referred to as pyridinium/di- $N$-chloramine cotton in the study. 


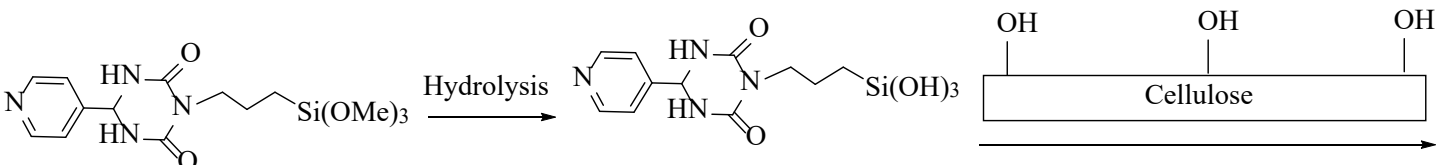

$$
\mathrm{C}_{6} \mathrm{H}_{13}
$$<smiles>NC(N)c1ccncc1</smiles>

$$
\lambda_{N} \lambda_{0}
$$

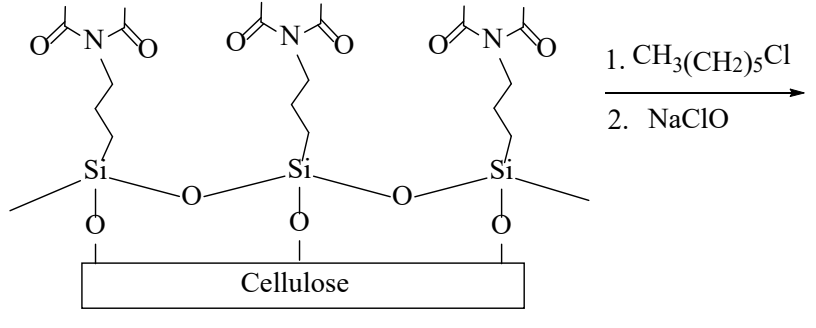<smiles>NCc1ccncc1</smiles>

$\lambda_{\mathrm{N}}$

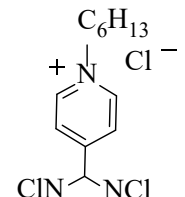

$$
\text { 管 }
$$

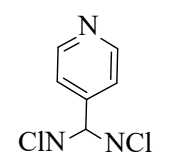

入

\section{$\mathrm{C}_{6} \mathrm{H}_{13}$}

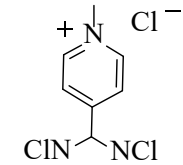

$\mathrm{ClN}_{\mathrm{NCl}}$ ${ }^{\lambda}{ }_{\mathrm{N}}$

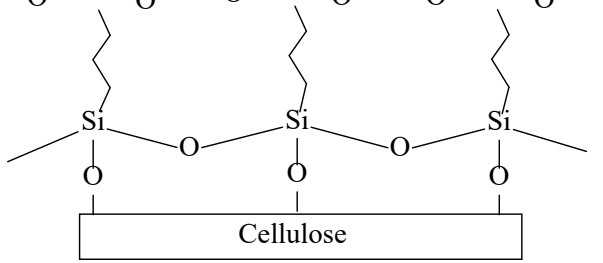

Scheme 2. Preparation of pyridinium/di- $N$-chloramine cotton

\section{Evaluation of the amount of oxidative chlorine}

The determination of the total amount of oxidative chlorines $\left(\mathrm{Cl}^{+}\right)$is necessary for biocidal analysis and comparison with other systems. The total amount is evaluated using an iodometric/thiosulfate titration method from the formula below (Cerkez I et al., 2016; Zhang S et al., 2019):

$$
C l^{+} \%=35.5 / 2 N \times\left(V_{C l^{+}}-V_{0}\right) \times 100 / W
$$

Where $\mathrm{N}$ is the concentration $(\mathrm{mol} / \mathrm{L})$ of the $\mathrm{Na}_{2} \mathrm{~S}_{2} \mathrm{O}_{3}$ titration solution, $V_{C l}{ }^{+}$and $V_{0}$ represent volumes (L) of $\mathrm{Na}_{2} \mathrm{~S}_{2} \mathrm{O}_{3}$ solution consumed in the titrations of pyridinium/di$N$-chloramine cotton swatches and controls, respectively, and $W$ denotes the weight in grams of the titration swatches.

\section{Evaluation of biocidal efficacy}

Biocidability of pyridinium/di- $N$-chloramine cotton samples was evaluated using grampositive $S$. aureus and gram-negative $E$. coli as representative bacteria in accordance with the "sandwich test" method (Sun Y and G Sun, 2004; Zhao N and S Liu, 2011).

Both bacteria were allowed to grow at $37^{\circ} \mathrm{C}$ under $250 \mathrm{rpm}$ overnight in broth medium. 
Afterwards, the cells were centrifugally harvested, washed and diluted with phosphate buffered saline (PBS) solution to prepare suspensions of known concentrations (CFU). $50 \mu \mathrm{L}$ of each bacterial suspension was sandwiched in the center of two $1 \mathrm{in}^{2}$ pyridinium/di- $N$-chloramine cotton swatches that sufficiently contacted with the suspension by placing a weight on the top. After contact time of 3, 5, and 10 min, the remaining $N$-chloramine sites of swatches were quenched with $10 \mathrm{~mL}$ of sterile $0.02 \mathrm{~N}$ $\mathrm{Na}_{2} \mathrm{~S}_{2} \mathrm{O}_{3}$ in a centrifuge tube. After vortex, serial dilutions of the quenched suspension with PBS were placed on Luria-Bertani agar plates at $37^{\circ} \mathrm{C}$ overnight for record of the number of colonies to calculate antibacterial efficacy. Some pyridinium/di- $N$ chloramine cotton swatches were first quenched with excessive $0.02 \mathrm{~N} \mathrm{Na}_{2} \mathrm{~S}_{2} \mathrm{O}_{3}$ and subsequently subjected to evaluation following the same procedure for the analysis of biocidal efficacy of pyridinium functionality only (denoted as pyridinium functionalized cotton). Pristine cotton swatches without any modification were used as the controls. Each sample was assayed in triple and the average value was reported.

\section{Investigation of biocidal durability and rechargeability}

The durability and rechargeability of the $N$-chloramine sites in the modifier provide crucial information of the application value of the pyridinium/di- $N$-chloramine cotton. The effects of washings, UV irradiation and storage on durability and rechargeability of the $\mathrm{N}$-chloramine sites were then assayed. The durability and the rechargeability of $\mathrm{N}-\mathrm{Cl}$ bonds under repeat washings were evaluated using AATCC Test Method 61-1996 (Cerkez I et al., 2011). Pyridinium/di- $N$-chloramine cotton swatches with a size of $1 \times 2$ inch were subjected to repeat washing cycles in $150 \mathrm{~mL}$ of $0.15 \mathrm{wt} \%$ 
aqueous AATCC detergent solution in a canister containing 50 stainless steel balls. The canister ran at $49{ }^{\circ} \mathrm{C}$ and $42 \mathrm{rpm}$ for $45 \mathrm{~min}$ to accomplish one washing cycle that is equivalent of five machine washings. After 5, 10 and 15 washing cycles, each sample was washed for three times with distilled water, dried at ambient temperature afterwards, and then titrated for the determination of oxidative chlorines. Some washed samples were recharged with $\mathrm{NaClO}$ solution following previously described process and then titrated to assay the durability of the biocidal silicone layer and the rechargeability of hydrolyzed $N$-chloramine sites. Each reported value was averaged over three measurements.

The durability and rechargeability of the $N$-chloramine sites in the modifier of pyridinium/di- $N$-chloramine cotton swatch under UV irradiation $(340 \mathrm{~nm})$ were tested in an accelerated weathering tester (Q8 model, Hongzhan Group) at $25 \% \mathrm{RH}$ and $20^{\circ} \mathrm{C}$ over a 7-day period. For each period, one set of irradiated swatches was directly titrated for the determination of the amount of the remaining oxidative chlorine, and a second set was rechlorinated using $\mathrm{NaClO}$ solution and then titrated for the estimation of the proton-initiated decomposition of the silicone modifier and $N$-chloramine sites.

The storage stability of the biocidal function was evaluated by keeping pyridinium/di- $N$-chloramine cotton swatches at $25{ }^{\circ} \mathrm{C}$ and $65 \% \mathrm{RH}$ under laboratory light over a 30-day period. Some swatches were titrated directly and some were rechlorinated and then titrated to investigate the storage stability of $\mathrm{N}$-chloramine structures. 


\section{Results and discussion}

Preparation of 6-(pyridin-4-yl)-1,3,5-triazinane-2,4-dione

The first step is the reaction of biuret with isonicotinaldehyde to produce 6-(pyridin-4yl)-1,3,5-triazinane-2,4-dione as shown in Scheme 1. The success of the reaction is verified with FTIR measurements as shown in Fig. 1. The spectrum of biuret (Fig. 1a) shows the asymmetric and symmetric stretching vibrations of primary amidic $\mathrm{N}-\mathrm{H}$ at 3421 and $3336 \mathrm{~cm}^{-1}$, the stretching vibration of imidic $\mathrm{N}-\mathrm{H}$ at $3197 \mathrm{~cm}^{-1}$, the stretching vibration of $\mathrm{C}=\mathrm{O}$ centered at $1705 \mathrm{~cm}^{-1}$, and the in-plane deformation vibration of primary amidic $\mathrm{N}-\mathrm{H}$ in the region of 1577 to $1617 \mathrm{~cm}^{-1}$. The spectrum of isonicotinaldehyde (Fig. 1b) shows aldehyde mode of C-H stretching vibration at 2841 and $2745 \mathrm{~cm}^{-1}, \mathrm{C}=\mathrm{O}$ stretching vibration at $1713 \mathrm{~cm}^{-1}$, and $\mathrm{C}=\mathrm{N}$ stretching vibration at $1594 \mathrm{~cm}^{-1}$. The spectrum of 6-(pyridin-4-yl)-1,3,5-triazinane-2,4-dione (Fig. 1c) shows features from the two reactants. The peaks originating from biuret include the one at $3298 \mathrm{~cm}^{-1}$ that is ascribed to amidic $\mathrm{N}-\mathrm{H}$ stretching vibration, the peak at 3150 $\mathrm{cm}^{-1}$ that is attributed to imidic $\mathrm{N}-\mathrm{H}$ stretching vibration, and the peak at $1691 \mathrm{~cm}^{-1}$ that is ascribed to $\mathrm{C}=\mathrm{O}$ stretching vibration, respectively. The band at $1600 \mathrm{~cm}^{-1}$ is arise from $\mathrm{C}=\mathrm{N}$ stretching vibration of pyridine originating from isonicotinaldehyde. 


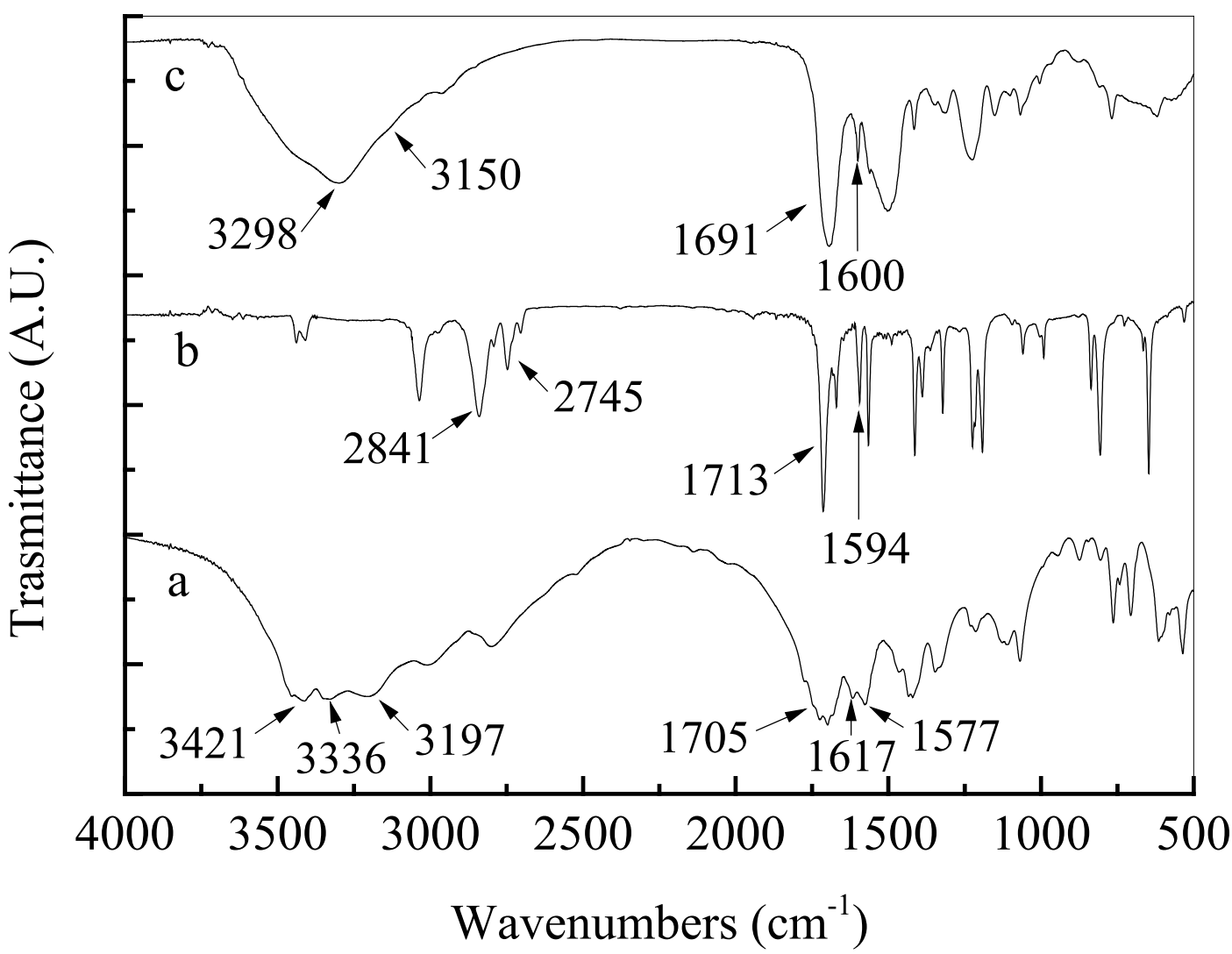

Fig. 1 FTIR spectra of biuret (a), isonicotinaldehyde (b), and 6-(pyridin-4-yl)-1,3,5-triazinane-2,4dione (c)

\section{Biocidal modification of cotton fibers}

The synthesis and hydrolysis of the silane monomers and subsequent condensation polymerization of the hydrolyzates on cotton are accomplished using a convenient onepot procedure as previously illustrated in Scheme 2 . The success of the formation of the silicone modifier cotton can be verified by comparison of the FTIR spectra of cotton before (Fig.2a) and after the polymerization (Fig.2b). After the polymerization, the spectrum of the sample (referred to as silane modified cotton) shows characteristic bands originating from the silicone unit including the amidic $\mathrm{N}-\mathrm{H}$ stretching vibration at $3248 \mathrm{~cm}^{-1}$, the $\mathrm{C}=\mathrm{O}$ stretching vibration at $1690 \mathrm{~cm}^{-1}$, the $\mathrm{C}=\mathrm{N}$ stretching vibration at $1602 \mathrm{~cm}^{-1}$, Si-O-C stretching vibration and $1259 \mathrm{~cm}^{-1}$ and the $\mathrm{Si}-\mathrm{O}-\mathrm{Si}$ stretching 
vibration at $800 \mathrm{~cm}^{-1}$. Next modification is to quaternize the pyridine rings in the modifier to pyridinium ions with 1-chlorohexane to produce quaternized cotton. Correspondingly, the stretching vibration of $\mathrm{C}=\mathrm{N}$ at $1602 \mathrm{~cm}^{-1}$ was shifted to higher frequencies and merged with binding vibration of $\mathrm{O}-\mathrm{H}$ at $1639 \mathrm{~cm}^{-1}$ as shown in Fig. 2c. Eventually, the two amidic $\mathrm{N}-\mathrm{H}$ in each unit were chlorinated to $\mathrm{N}$-chloramines with $\mathrm{NaClO}$ to produce pyridinium/di-N-chloramine cotton, which resulted in the disappearance of $\mathrm{N}-\mathrm{H}$ stretching vibration at $3259 \mathrm{~cm}^{-1}$ and a blueshift of $\mathrm{C}=\mathrm{O}$ stretching mode from $1689 \mathrm{~cm}^{-1}$ to a higher frequency of $1724 \mathrm{~cm}^{-1}$. The bluefshift is the evidence of the breakage of $\mathrm{N}-\mathrm{H} \cdots \mathrm{O}=\mathrm{C}$ hydrogen bonding and increase of atomic weight resulted from the transformation of $\mathrm{N}-\mathrm{H}$ to $\mathrm{N}-\mathrm{Cl}$ (Kocer $\mathrm{H} B$ et al., 2011; Sun Y and G Sun, 2001). 


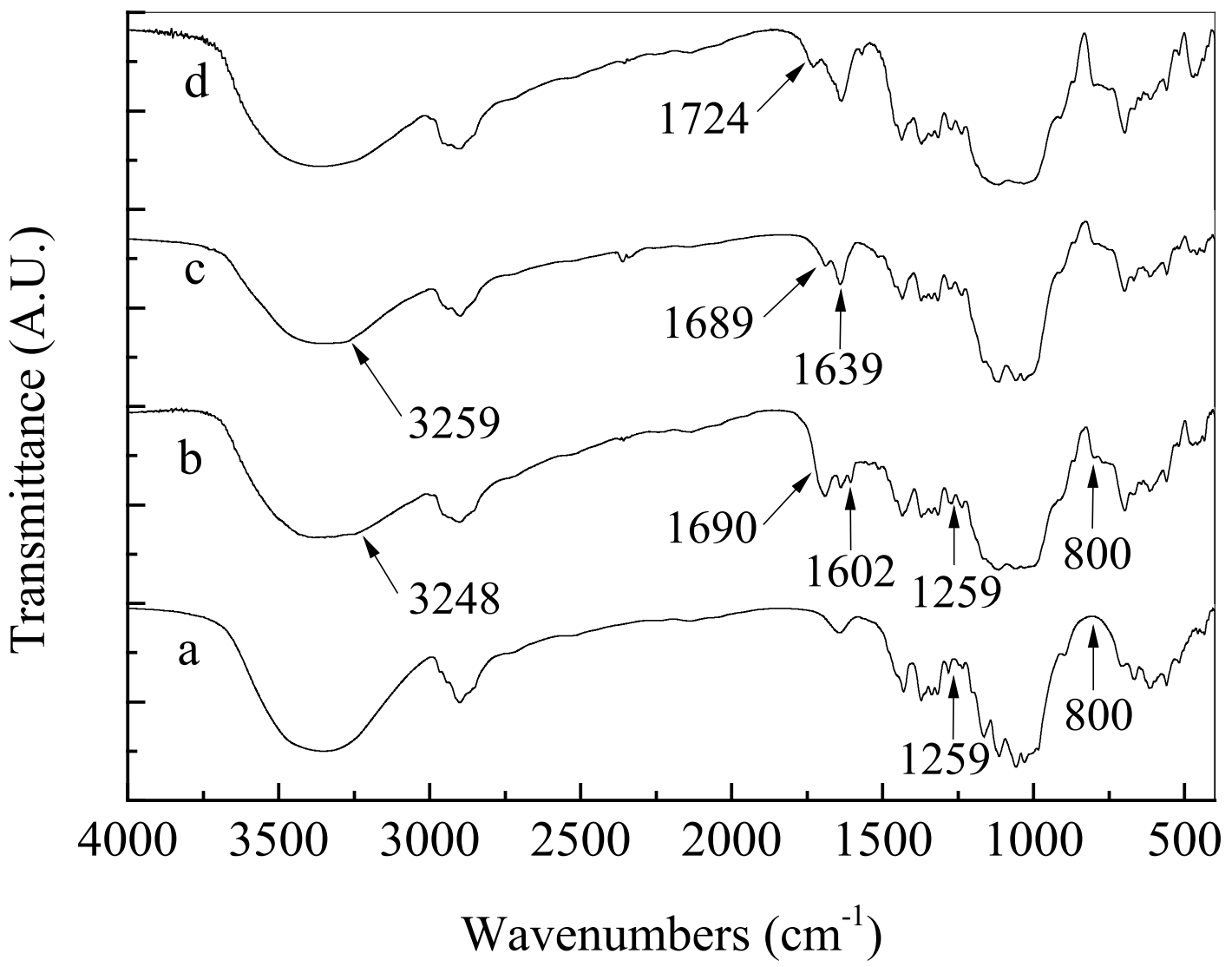

Fig. 2 FTIR spectra of pristine cotton (a), silane modified cotton (b), quaternized cotton (c), and pyridinium/di- $N$-chloramine cotton

Other characterization is required for unequivocally confirmation since the coating is relatively thin, which in turn leads to subtle of changes of some FTIR signals. In this sense, XPS spectra are good supplements since this technique is very surface sensitive and only acquires chemical compositions of the top $\sim 5 \mathrm{~nm}$ when placing a sample at a test angle of $45^{\circ}$ with respect to the X-ray beam. In contrast of the one of original cotton that only displays signals of carbon $\left(\mathrm{C}_{1 \mathrm{~s}}\right)$ at $285 \mathrm{eV}$ and oxygen $\left(\mathrm{O}_{1 \mathrm{~s}}\right)$ at $533 \mathrm{eV}$, the XPS survey scan of pyridinium/di- $N$-chloramine cotton exhibits additional photoelectron peaks at 102, 153, 202, 272, $401 \mathrm{eV}$ as illustrated in Fig. 3b, which agree well with binding energies of $\mathrm{Si}_{2 \mathrm{p}}, \mathrm{Si}_{2 \mathrm{~s}}, \mathrm{Cl}_{2 \mathrm{p}}, \mathrm{Cl}_{2 \mathrm{~s}}$, and $\mathrm{N}_{1 \mathrm{~s}}$. These new characteristic peaks witness the presence of the biocidal coating layer on cotton fibers. 


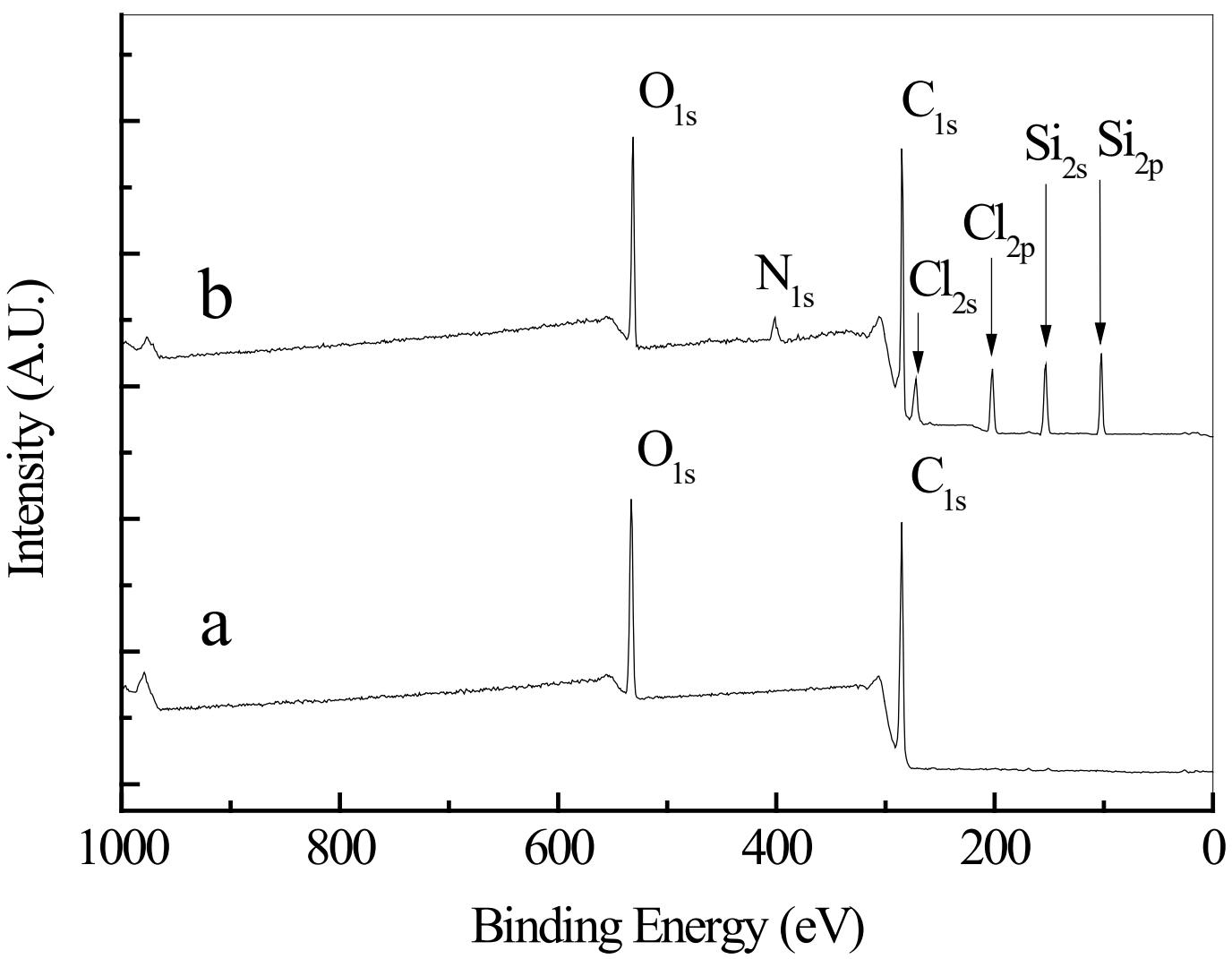

Fig. 3 XPS survey scans of pure cotton (a) and pyridinium/di- $N$-chloramine cotton (b)

The chemical states of nitrogen and chlorine are further examined with highresolution spectra to ensure the correct formats of pyridinium and $\mathrm{N}$-chloramine on pyridinium/di- $N$-chloramine cotton. As shown in Scheme 2, there are four types of nitrogen according to the chemical environments. The $\mathrm{N}_{1 s}$ peak was correspondingly fitted into components at $402.2 \mathrm{eV}$ for the cationic nitrogen in pyridinium ions (Chen Y et al., 2015), at 400.6 eV for covalent nitrogen in imide bond (Dong A et al., 2014), at $399.8 \mathrm{eV}$ for covalent nitrogen in amide $N$-chloramine (Tamura A et al., 2012), and at $399.1 \mathrm{eV}$ (Chen Y et al., 2015) for residual pyridine due to the incompletion of quaternization with an areal ratio of $\sim 0.7: 1: 2: 0.3$ as shown in Fig. 4a. The $\mathrm{Cl}_{1 \text { s }}$ peak of the coating was similarly curve-fitted into two components at $200.5 \mathrm{eV}$ for the covalent chlorine in $\mathrm{N}$-chloramine and at $197.2 \mathrm{eV}$ for the anionic chlorine in pyridinium ion 

chlorination.

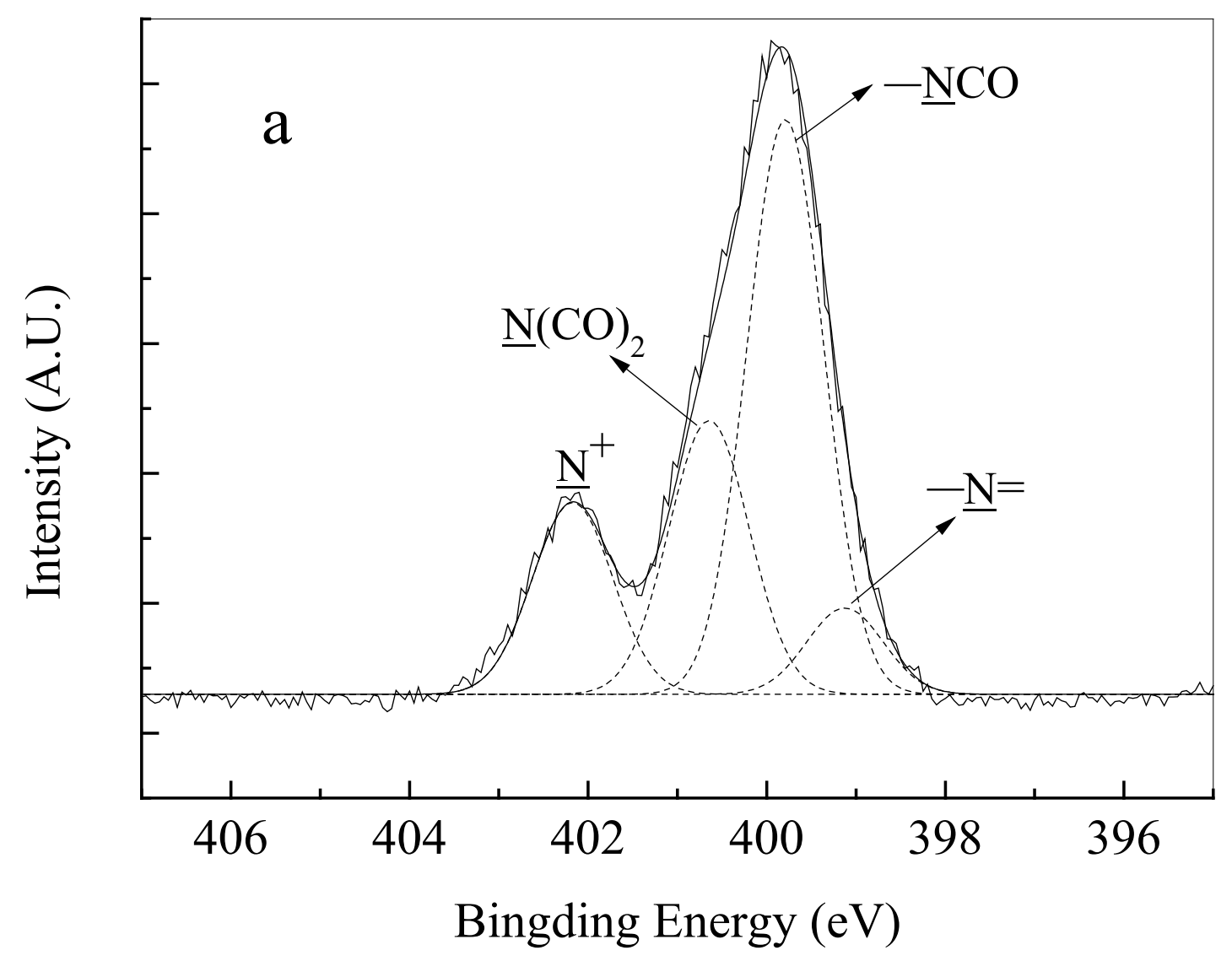




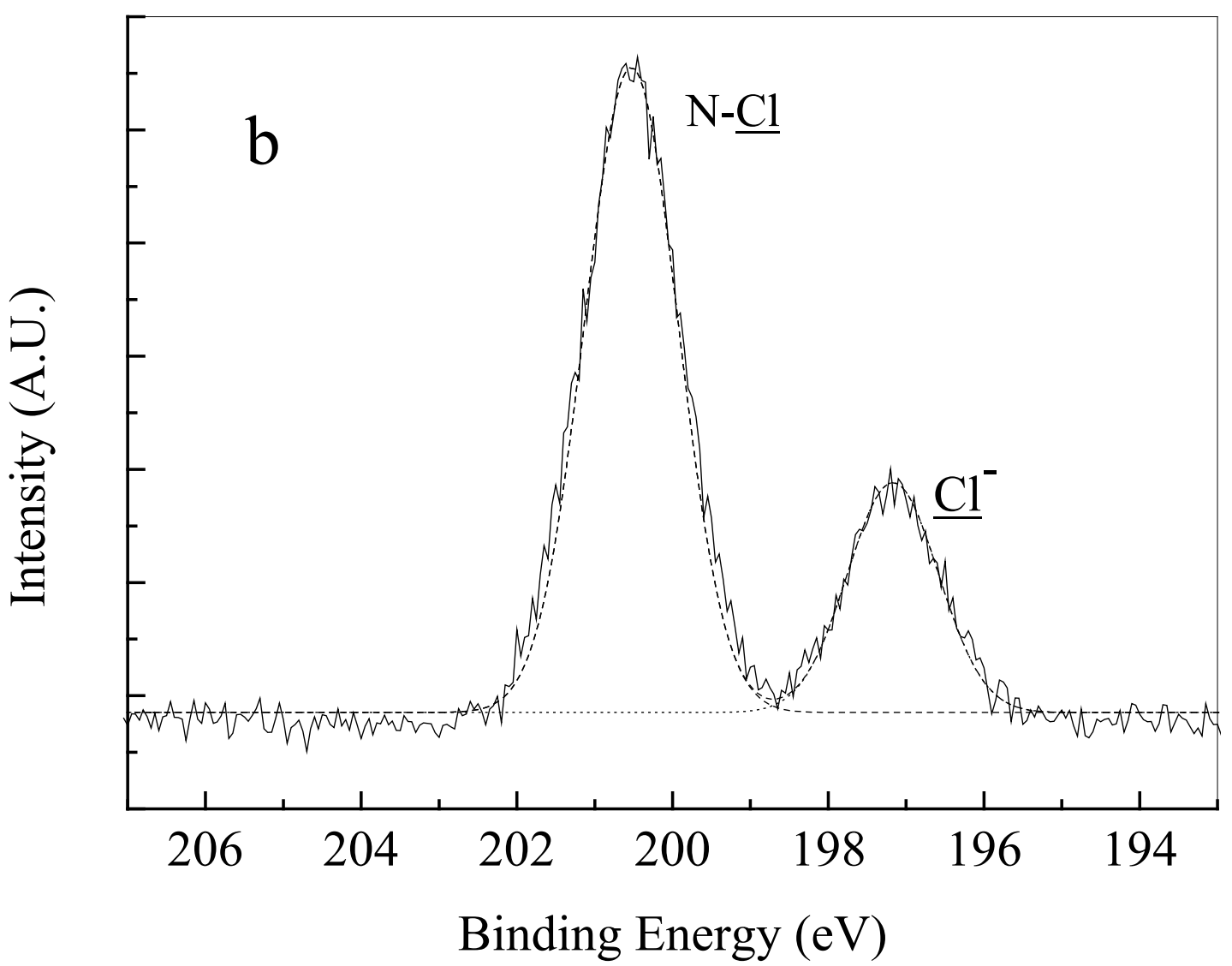

Fig. 4 XPS high resolution spectra and deconvolutions of $\mathrm{N}_{1 \mathrm{~s}}$ (a) and $\mathrm{Cl}_{2 \mathrm{p}}$ (b)

After confirmation of its existence, the coating layer on pyridinium/di- $N$ chloramine cotton fibers was observed using SEM for morphology analysis. Compared with the original ones (Fig. 5a) that have smooth surfaces, the pyridinium/di- $N$ chloramine cotton fibers (Fig. 5b) were tightly surrounded with continuous coating layers without cracks or agglomerates. The full coverage ensures good contact with bacterial suspension and hence is positive for the biocidal application. 


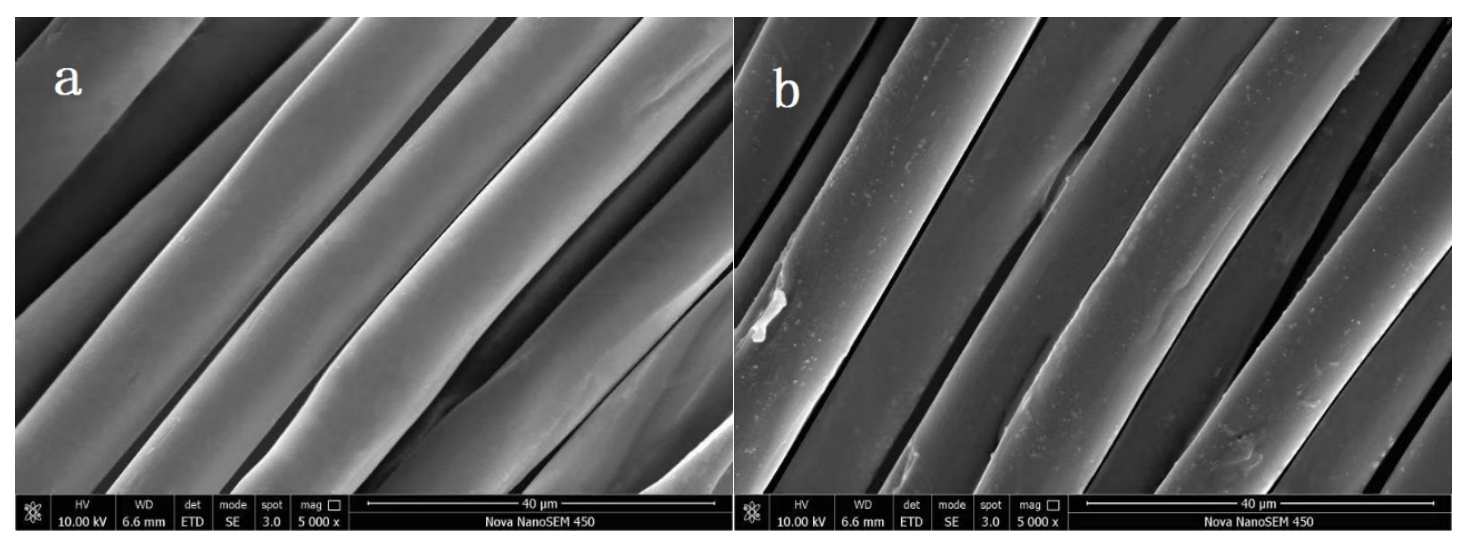

Fig. 5 SEM images of pristine (a) and pyridinium/di- $N$-chloramine (b) cotton fibers

The thickness of a modification layer on a substrate is commonly estimated from the image of cross-section. However, the fibers herein are coated with a biocidal silicone. Silicones are highly elastic and have very low glass-transition temperatures, which in turn hinders the acquisition of an accurate cross-section of silicone-coated fibers even with freeze-cutting technique (Przybylak M et al., 2018). The thickness of the modifier was then estimated to be $136.8 \mathrm{~nm}$ by using a method based on the weight of the coating from the following equation:

$$
t=d\left(W_{1}-W_{0}\right) \rho_{\mathrm{C}} / 4 W_{0} \rho_{\mathrm{P}}
$$

where $t$ denotes the thickness of the biocidal layer; $d$ is the diameter of the original cotton fiber; $W_{0}$ and $W_{1}$ are weights of the fibers before and after modification, respectively; $\rho_{C}$ and $\rho_{\mathrm{p}}$ mean densities of the cotton cellulose and the biocidal silicone modifier, respectively. In addition, the concentration of oxidative chlorine is calculated to be $0.24 \mathrm{wt} \%$ by the previously described iodometric/thiosulfate titration from equation 1.

Assessment of biocidal performance

The biocidability of pyridinium/di- $N$-chloramine cotton swatches was tested using $S$. 
aureus and E. coli as model species. As what the biocidal data of kinetics showed in Table 1, pristine cotton swatches (controls) was not biocidal since the small losses of $S$. aureus $(0.20 \mathrm{log})$ and E. coli $(0.17 \mathrm{log})$ after $10 \mathrm{~min}$ contact time were resulted from adhesion of microorganisms to fibers and natural mortality (Ren X et al., 2008). In contrast, the pyridinium/di- $N$-chloramine cotton swatches were highly biocidal and imparted complete inactivation of both strains within $3 \mathrm{~min}$.

Since our hypothesis is that the combination of one cationic center and more than one $\mathrm{N}$-chloramines leads to intensified synergism, a higher biocidal efficacy than not only monofunctionality but also basic synergistic integration of one cationic center and one $N$-chloramine, the comparisons of our combination with those cases are needed for verification.

The biocidal performance our combination of one cationic pyridinium and two amide $N$-chloramines was firstly compared with non-synergistic single functionality (pyridinium or $N$-chloramines). Pyridinium functionalized cotton swatches that were formed by quenching the $N$-chloramine sites of pyridinium/di- $N$-chloramine cotton swatches with $\mathrm{Na}_{2} \mathrm{~S}_{2} \mathrm{O}_{3}$ solution showed much lower biocidal efficacies (only $1.50 \mathrm{log}$ reduction for $S$. aureus and $0.81 \log$ reduction for $E$. coli after $10 \mathrm{~min}$ ) as shown in Table 1 since pyridinium salts are well-known mild biocidal groups. Furthermore, the pyridinium functionalized cotton swatches showed higher inactivation rate against $S$. aureus than $E$. coli due to the thicker membrane of $E$. coli that in turn leads to more resistance to the penetration of pyridinium structures (Hu B et al., 2014; Liang J et al., 2006). This low efficacy is, however, still desirable, especially after the $N$-chloramines 
of the combined units are consumed and not rechlorinated yet. $N$-chloramine silane functionalized cotton with similar loadings of $\mathrm{Cl}^{+}$was also less biocidal than pyridinium/di- $N$-chloramine cotton since an amide $N$-chloramine silane coated cotton with $\mathrm{Cl}^{+}$loading of $0.23 \mathrm{wt} \%$ only fully eliminated $S$. aureus and $E$. coli within a contact time of 10 and 30 min, respectively (Cheng X et al., 2015). Therefore, our presented combination is more efficient than single functionality of both pyridinium and $\mathrm{N}$ chloramine. This is believed that the hydrophilic cationic salt not only overcomes the hydrophobicity of $N$-chloramine but also electronically draws bacteria to $N$-chloramine, assisting the contact and killing process.

Our combination is then compared with basic synergism of one pyridinium and one $N$-chloramine. It still took a longer contact time of 10 min for cotton swatches of basic synergism (one pyridinium and one $N$-chloramine) with higher loading of $\mathrm{Cl}^{+}$ (0.32 wt\%) to completely kill S. aureus and E. coli (Chen Y et al., 2019), proving the intensified synergism of our design. This is because antibacterial ability is a surface property and hence only the ones on the top surface instead of the overall biocidal groups can participate in contact-killing process. The increase of the ratio of more powerful $\mathrm{N}$-chloramine in a composite unit naturally results in a higher surface concentration of $\mathrm{N}$-chloramine compared with basic synergistic counterparts, achieving the observed intensified synergism. The intensified synergism can then be used as a strategy for design of more powerful biocidal functionalities. 
Table 1 Biocidal performances of different cotton samples against S. aureus and E. coli

\begin{tabular}{cccc}
\hline \multirow{2}{*}{ Material } & $\begin{array}{c}\text { Contact Time } \\
(\mathrm{min})\end{array}$ & $\begin{array}{c}\text { Log reduction of } \\
\text { E. coli. }\end{array}$ & $\begin{array}{c}\text { Log reduction of } \\
\text { Control }\end{array}$ \\
\hline & 5 & 0.02 & 0.02 \\
& 10 & 0.05 & 0.06 \\
Pyridinium & 3 & 0.17 & 0.20 \\
functionalized cotton & 5 & 0.29 & 0.38 \\
& 10 & 0.44 & 0.66 \\
Pyridinium/di- $N-$ & 3 & 0.81 & 1.50 \\
chloramine cotton & 5 & 7.62 & 7.55 \\
\hline
\end{tabular}

S. aureus and E. coli at inoculum populations of $3.57 \times 10^{7}$ and $4.17 \times 10^{7} \mathrm{CFU}$, respectively.

\section{Stability of biocidal performance}

Stable and regenerable biocidal performance is very desirable for practical applications. The chemistry of the biocidal coating layer is a silicone since its main chain is composed of $-\mathrm{Si}-\mathrm{O}-$ units. Studies have verified that silicones are ideal carriers of functional pendants since they are nontoxic polymers with a sturdy and hydrophobic backbone that ensures safe and long-lasting biocidal performance even under intense usages (Chen Y et al., 2019; Zhao J et al., 2015). Additionally, silicones can be photodecomposed into inorganic $\mathrm{SiO}_{\mathrm{x}}$ that shields beneath compositions from further photolysis (Ouyang M et al., 2000; Phely-Bobin T S et al., 2000), increasing the stability of the biocidal coating layer. The stability and rechargeability of oxidative chlorines on pyridinium/di- $N$-chloramine cotton swatches under repeat washings are summarized in Table 2. The content of oxidative chlorines on pyridinium/di- $N$ chloramine cotton decreased gradually as the increase of the number of washing cycles, 
losing a $83 \%$ of initial loading (from 0.24 to $0.04 \mathrm{wt} \%$ ) after 15 washing cycles (equivalence of 75 machine washing cycles). The rechargeability of lost chlorines is promising since the content reached $0.10 \mathrm{wt} \%$, corresponding to a $42 \%$ rechargeability, after 15 washing cycles by rechlorination with $\mathrm{NaClO}$. It is believed that the recoverable parts of lost chlorines are caused by hydrolysis of $\mathrm{N}-\mathrm{Cl}$ to $\mathrm{N}-\mathrm{H}$ and the non-recoverable ones are caused by peeling of biocidal silicone coating during washings.

Table 2 Washing stability of coating on pyridinium/di- $N$-chloramine cotton

\begin{tabular}{ccc}
\hline No. of washing cycles & $\begin{array}{c}\text { Remained chlorines } \\
\left(\mathrm{wt} \% \mathrm{Cl}^{+}\right)\end{array}$ & $\begin{array}{r}\text { Recovered chlorines after } \\
\text { rechlorination }\left(\mathrm{wt} \% \mathrm{Cl}^{+}\right)\end{array}$ \\
\hline 0 & 0.24 & 0.24 \\
5 & 0.11 & 0.15 \\
10 & 0.07 & 0.13 \\
15 & 0.04 & 0.10 \\
\hline
\end{tabular}

Similarly, UV photolysis can also induce permanent loss (decomposition of the biocidal layer) and temporary loss (cleavage of $\mathrm{N}-\mathrm{Cl}$ ) of $\mathrm{N}$-chloramine sites. Data in Table 3 shows that the loading of oxidative chlorines radically decreased within $1 \mathrm{~h}$, losing $49 \%$ of oxidative chlorine. Then, the loss gradually increased with the increase of irradiation time, losing $93 \%$ and $100 \%$ of initial value at $24 \mathrm{~h}$ and $7 \mathrm{~d}$. However, $96 \%, 61 \%$ and $52 \%$ of oxidative chlorines were recharged after the swatches were shined for $1 \mathrm{~h}, 24 \mathrm{~h}$ and $7 \mathrm{~d}$ and rechlorinated. The retentivity and rechargeability of oxidative chlorines under UV irradiation are both better than some non-silicone 
coatings (Cerkez I et al., 2011; Jiang Z et al., 2014) due to the previously mentioned shielding effect of $\mathrm{SiO}_{x}$. In those literatures, Cerkez and coworkers reported 54\%, 68\%, and $100 \%$ losses of chlorines after irradiation for $1 \mathrm{~h}, 2 \mathrm{~h}$, and $24 \mathrm{~h}$, respectively, while Jiang and coworkers observed a 100\% loss of chlorines after irradiation for only $3 \mathrm{~h}$. In addition, UV absorbing effect of pyridinium could also contribute to the photolytic stability of the coating (Li L et al., 2016).

Table 3 UV stability of the biocidal silicone coating on pyridinium/di- $N$-chloramine cotton

\begin{tabular}{|c|c|c|c|c|c|c|c|}
\hline Exposure Time & $1 \mathrm{~h}$ & $2 \mathrm{~h}$ & $4 \mathrm{~h}$ & $8 \mathrm{~h}$ & $12 \mathrm{~h}$ & $24 \mathrm{~h}$ & $7 d$ \\
\hline $\begin{array}{l}\text { Percentage of } \\
\text { remained chlorine }\end{array}$ & $51 \%$ & $38 \%$ & $26 \%$ & $18 \%$ & $12 \%$ & $7 \%$ & $0 \%$ \\
\hline $\begin{array}{l}\text { Percentage of } \\
\text { recovered chlorine }\end{array}$ & $96 \%$ & $92 \%$ & $86 \%$ & $78 \%$ & $71 \%$ & $61 \%$ & $52 \%$ \\
\hline
\end{tabular}

The biocidal modifier adsorbs moisture from air under storage, which in turn leads to the hydrolysis of $\mathrm{N}$-chloramine structures to $\mathrm{N}-\mathrm{H}$ moieties. The remained and recovered chlorines as a function of long-term storage are shown in Table 4. The chlorine loading gradually decreased from $0.24 \mathrm{wt} \%$ to $0.11 \mathrm{wt} \%$ (a loss of $54 \%$ ) within 30 days under laboratory light at $25{ }^{\circ} \mathrm{C}$ and $65 \% \mathrm{RH}$. However, $\sim 83 \%$ of chlorines was recovered by rechlorination for the samples stored for $30 \mathrm{~d}$. The good retentivity under long-term storage is attributed to the hydrophobicity of silicone main chains to prevent moisture-triggered hydrolysis of $\mathrm{N}$-chloramine structures. In contrast, $\sim 85 \% \mathrm{Cl}^{+}$loss was measured in a hydrophilic chitosan-based coating that absorbed a 
large amount of moisture from the surroundings that caused rapid hydrolysis of $\mathrm{N}$ chloramine sites under the same conditions for 30 days (Cao Z and Y Sun, 2008). Therefore, the biocidal performance of the modified cotton is anticipated to be well preserved after a relatively extended storage period.

Table 4 Storage stability of the biocidal silicone coating on pyridinium/di- $N$-chloramine cotton

\begin{tabular}{ccccc}
\hline Storage time (day) & 0 & 10 & 20 & 30 \\
\hline Remained chlorines & 0.24 & 0.20 & 0.15 & 0.11 \\
$\quad\left(\mathrm{wt} \% \mathrm{Cl}^{+}\right)$ & & & & \\
\hline Recovered chlorines & 0.24 & 0.23 & 0.22 & 0.20 \\
$\left(\mathrm{wt} \% \mathrm{Cl}^{+}\right)$ & & & & \\
\hline
\end{tabular}

The above results verified that the increase of the ratio of $N$-chloramine in a composite unit of cationic center/ $\mathrm{N}$-chloramine is a strategy for deign of biocides with intensified synergism for antibacterial modification of substrates.

\section{Conclusions}

A silane, 6-(pyridin-4-yl)-3-(3-(trimethoxysilyl)propyl)-1,3,5-triazinane-2,4-dione, was synthesized for condensation polymerization on cotton to form a silicone coating. After quaternization and chlorination, each silicone unit is designed to have one cationic pyridinium and two amide $N$-chloramines. The results proved the hypothesis that the increase of $\mathrm{N}$-chloramine in a composite unit leads to intensified synergism, a higher biocidability even than basic synergism of one cationic center and one $\mathrm{N}$-chloramine. In addition, the design employs cyclic and hydrophilic $N$-chloramine, UV adsorbing pyridinium, and sturdy and UV-resistant silicone backbone. These virtues ensure 
promising durability and recoverability of antibacterial functionality under repeat washings, UV irradiation and long-term storage. The pyridinium/di- $N$-chloramine cotton therefore has superior biocidability and stability for practical usage.

\section{Acknowledgements}

This work was supported by the Natural Science Foundation of Shandong Province [Grant No. ZR2020ME083].

\section{References:}

Ates, B., Cerkez, I. (2017) Dual antibacterial functional regenerated cellulose fibers. J. Appl. Polym. Sci. 134: 44872.

Cao, Z., Sun, Y. (2008) N-halamine-based chitosan: Preparation, characterization, and antimicrobial function. J. Biomed. Mater. Res., Part A 85: 99-107.

Cerkez, I., Kocer, H.B., Worley, S.D., Broughton, R.M., Huang, T.S. (2011) N-halamine biocidal coatings via a layer-by-layer assembly technique. Langmuir 27: 4091-4097.

Cerkez, I., Kocer, H.B., Worley, S.D., Broughton, R.M., Huang, T.S. (2016) Antimicrobial functionalization of poly(ethylene terephthalate) fabrics with waterborne N-halamine epoxides. J. Appl. Polym. Sci. 133: 43088.

Chen, X., Hu, B., Xing, X., Liu, Z., Zuo, Y., Xiang, Q. (2015) Preparation of grafted cationic polymer/silver chloride modified cellulose fibers and their antibacterial properties. J. Appl. Polym. Sci. 132: 42092.

Chen, Y., Han, Q., Wang, Y., Zhang, Q., Qiao, X. (2015) Synthesis of pyridinium polysiloxane for antibacterial coating in supercritical carbon dioxide. J. Appl. Polym. Sci. 132: 41723. 
Chen, Y., Ma, Y., He, Q., Han, Q., Zhang, Q., Chen, Q. (2019) Construction of pyridinium/N-chloramine polysiloxane on cellulose for synergistic biocidal application. Cellulose 26: 5033-5049.

Chen, Y., Niu, M., Yuan, S., Teng, H. (2013) Durable antimicrobial finishing of cellulose with QSA silicone by supercritical adsorption. Appl. Surf. Sci. 264: 171-175. Chen, Y., Wang, Y., Feng, C., He, Q., Chen, Q., Wang, Z., Han, Q. (2020) Novel quat/di$\mathrm{N}$-halamines silane unit with enhanced synergism polymerized on cellulose for development of superior biocidability. Int. J. Biol. Macromol. 154: 173-181.

Cheng, X., Li, R., Du, J., Sheng, J., Ma, K., Ren, X., Huang, T.-S. (2015) Antimicrobial activity of hydrophobic cotton coated with N-halamine. Polym. Adv. Technol. 26: 99103.

Ding, X., Duan, S., Ding, X., Liu, R., Xu, F.-J. (2018) Versatile antibacterial materials: an emerging arsenal for combatting bacterial pathogens. Adv. Funct. Mater. 28: 1802140.

Dong, A., Xue, M., Lan, S., Wang, Q., Zhao, Y., Wang, Y., Zhang, Y., Gao, G., Liu, F., Harnoode, C. (2014) Bactericidal evaluation of N-halamine-functionalized silica nanoparticles based on barbituric acid. Colloids Surf., B 113: 450-457.

Dong, A., Zhang, Q., Wang, T., Wang, W., Liu, F., Gao, G. (2010) Immobilization of cyclic N-Halamine on polystyrene-functionalized silica nanoparticles: synthesis, characterization, and biocidal activity. J. Phy. Chem. C 114: 17298-17303. 
El-Rafie, M., Ahmed, H.B., Zahran, M. (2014) Characterization of nanosilver coated cotton fabrics and evaluation of its antibacterial efficacy. Carbohydr. Polym. 107: 174181.

Gomes, A.P., Mano, J.F., Queiroz, J.A., Gouveia, I.C. (2015) Layer-by-layer assembly for biofunctionalization of cellulosic fibers with emergent antimicrobial agents. Adv. Polym. Sci. 2016: 225-240.

Hu, B., Chen, X., Zuo, Y., Liu, Z., Xing, X. (2014) Dual action bactericides: quaternary ammonium/N - halamine - functionalized cellulose fiber. J. Appl. Polym. Sci. 131: 40070.

Ibrahim, M.M., Mezni, A., El-Sheshtawy, H.S., Abu Zaid, A.A., Alsawat, M., El-Shafi, N., Ahmed, S.I., Shaltout, A.A., Amin, M.A., Kumeria, T., Altalhi, T. (2019) Direct Zscheme of $\mathrm{Cu} 2 \mathrm{O} / \mathrm{TiO} 2$ enhanced self-cleaning, antibacterial activity, and UV protection of cotton fiber under sunlight. Appl. Surf. Sci. 479: 953-962.

Jiang, Z., Ma, K., Du, J., Li, R., Ren, X., Huang, T. (2014) Synthesis of novel reactive N-halamine precursors and application in antimicrobial cellulose. Appl. Surf. Sci. 288: 518-523.

Kang, Z.-Z., Zhang, B., Jiao, Y.-C., Xu, Y.-H., He, Q.-Z., Liang, J. (2013) High-efficacy antimicrobial cellulose grafted by a novel quaternarized N-halamine. Cellulose 20: 885893.

Kocer, H.B., Cerkez, I., Worley, S.D., Broughton, R.M., Huang, T.S. (2011) Polymeric antimicrobial N-halamine epoxides. ACS Appl. Mater. Interfaces 3: 2845-2850. 
Kou, L., Liang, J., Ren, X., Kocer, H.B., Worley, S., Broughton, R., Huang, T. (2009) Novel N-halamine silanes. Colloids Surf., A 345: 88-94.

Krishnan, S., Ward, R.J., Hexemer, A., Sohn, K.E., Lee, K.L., Angert, E.R., Fischer, D.A., Kramer, E.J., Ober, C.K. (2006) Surfaces of fluorinated pyridinium block copolymers with enhanced antibacterial activity. Langmuir 22: 11255-11266.

Li, L., Pu, T., Zhanel, G., Zhao, N., Ens, W., Liu, S. (2012) New biocide with both N chloramine and quaternary ammonium moieties exerts enhanced bactericidal activity. Adv. Healthcare Mater. 1: 609-620.

Li, L., Zhao, Y., Zhou, H., Ning, A., Zhang, F., Zhao, Z. (2016) Synthesis of pyridinium $\mathrm{N}$-chloramines for antibacterial applications. Tetrahedron Lett.

Liang, J., Chen, Y., Barnes, K., Wu, R., Worley, S.D., Huang, T.S. (2006) Nhalamine/quat siloxane copolymers for use in biocidal coatings. Biomaterials 27: 24952501.

Liang, J., Wu, R., Wang, J.W., Barnes, K., Worley, S.D., Cho, U., Lee, J., Broughton, R.M., Huang, T.S. (2007) N-halamine biocidal coatings. J. Ind. Microbiol. Biotechnol. 34: $157-163$.

Liu, X.Y., Ma, L.L., Chen, F., Liu, J.Z., Yang, H., Lu, Z. (2019) Synergistic antibacterial mechanism of Bi2Te3 nanoparticles combined with the ineffective beta-lactam antibiotic cefotaxime against methicillin-resistant Staphylococcus aureus. J. Inorg. Biochem. 196: 8.

Liu, Y., Ma, K., Li, R., Ren, X., Huang, T.S. (2013) Antibacterial cotton treated with Nhalamine and quaternary ammonium salt. Cellulose 20: 3123-3130. 
Luo, G., Xi, G., Wang, X., Qin, D., Zhang, Y., Fu, F., Liu, X. (2017) Antibacterial N halamine coating on cotton fabric fabricated using mist polymerization. J. Appl. Polym. Sci. 134: 44897.

Luo, J., Sun, Y. (2006) Acyclic N - halamine - based fibrous materials: Preparation, characterization, and biocidal functions. J. Polym. Sci., Part A: Polym. Chem. 44: 35883600.

Ma, W., Wang, T., Li, H., Zhang, S. (2015) Cotton fabric modification through ceric (IV) ion-initiated graft copolymerisation of 2-methacryloyloxyethyltrimethyl ammonium chloride to enhance the fixation of reactive dyes. Cellulose 22: 4035-4047. Ouyang, M., Yuan, C., Muisener, R.J., Boulares, A., Koberstein, J.T. (2000) Conversion of some siloxane polymers to silicon oxide by UV/Ozone photochemical processes. Chem. Mater. 12: 1591-1596.

Phely-Bobin, T.S., Muisener, R.J., Koberstein, J.T., Papadimitrakopoulos, F. (2000) Preferential self-assembly of surface-modified $\mathrm{Si} / \mathrm{SiOx}$ nanoparticles on UV/Ozone micropatterned poly(dimethylsiloxane) films. Adv. Mater. 12: 1257-1261.

Przybylak, M., Maciejewski, H., Dudkiewicz, A., Walentowska, J., Foksowicz-Flaczyk, J. (2018) Development of multifunctional cotton fabrics using difunctional polysiloxanes. Cellulose 25: 1483-1497.

Qu, W., Yang, K., Liu, J., Liu, K., Liu, F.Q., Ji, J.H., Zhang, W. (2019) Precise management of chronic wound by nisin with antibacterial selectivity. Biomed. Mater. 14: 045008 
Ren, X., Akdag, A., Kocer, H.B., Worley, S., Broughton, R., Huang, T. (2009) Nhalamine-coated cotton for antimicrobial and detoxification applications. Carbohydr. Polym. 78: 220-226.

Ren, X., Kou, L., Liang, J., Worley, S.D., Tzou, Y.-M., Huang, T. (2008) Antimicrobial efficacy and light stability of N-halamine siloxanes bound to cotton. Cellulose 15: 593598.

Sodhi, R.N.S., Grad, H.A., Smith, D.C. (1992) Examination by X-ray photoelectron spectroscopy of the adsorption of chlorhexidine on hydroxyapatite. J. Dent. Res. 71: 1493-1497.

Sun, Y., Sun, G. (2001) Durable and refreshable polymeric N -halamine biocides containing 3-(4'-vinylbenzyl)-5,5-dimethylhydantoin. J. Polym. Sci., Part A: Polym. Chem. 39: 3348-3355.

Sun, Y., Sun, G. (2004) Novel refreshable N-halamine polymeric biocides: Nchlorination of aromatic polyamides. Ind. Eng. Chem. Res. 43: 5015-5020.

Tamura, A., Nishi, M., Kobayashi, J., Nagase, K., Yajima, H., Yamato, M., Okano, T. (2012) Simultaneous enhancement of cell proliferation and thermally induced harvest efficiency based on temperature-responsive cationic copolymer-grafted microcarriers. Biomacromolecules 13: 1765-1773.

Xu, Q., Ke, X., Cai, D., Zhang, Y., Fu, F., Endo, T., Liu, X. (2018) Silver-based, singlesided antibacterial cotton fabrics with improved durability via an 1-cysteine binding effect. Cellulose 25: 2129-2141. 
Zhang, S., Demir, B., Ren, X., Worley, S.D., Broughton, R.M., Huang, T.-S. (2019) Synthesis of antibacterial N-halamine acryl acid copolymers and their application onto cotton. J. Appl. Polym. Sci. 136.

Zhang, S., Li, R., Huang, D., Ren, X., Huang, T.-S. (2018a) Antibacterial modification of PET with quaternary ammonium salt and silver particles via electron-beam irradiation. Mater. Sci. Eng., C 85: 123-129.

Zhang, S., Yang, X., Tang, B., Yuan, L., Wang, K., Liu, X., Zhu, X., Li, J., Ge, Z., Chen, S. (2018b) New insights into synergistic antimicrobial and antifouling cotton fabrics via dually finished with quaternary ammonium salt and zwitterionic sulfobetaine. Chem. Eng. J. 336: 123-132.

Zhao, J., An, Q.F., Li, X.Q., Huang, L.X., Xu, X. (2015) A comblike polysiloxane with pendant quaternary ammonium polyether groups: Its synthesis, physical properties and antibacterial performance. J. Polym. Res. 22: 174.

Zhao, N., Liu, S. (2011) Thermoplastic semi-IPN of polypropylene (PP) and polymeric N-halamine for efficient and durable antibacterial activity. Eur. Polym. J. 47: 1654-1633. 


\section{Competing Interests}

The authors have no relevant financial or non-financial interests to disclose.

\section{Funding Info}

This work was supported by the Natural Science Foundation of Shandong Province [Grant No. ZR2020ME083].

\section{Author contribution}

Conceptualization, Methodology, Writing- Reviewing and Editing, Supervision,

Funding acquisition: Yong Chen

Investigation and Visualization: Yuyu Wang

Investigation: Zhendong Wang

Formal analysis: Qiang Zhang

Investigation and Resources: Qiuxia Han

\section{Data Availability}

All data generated or analysed during this study are included in this article.

\section{Animal Research}

Not applicable.

\section{Consent to Participate}

Not applicable.

\section{Consent to Publish}

Not applicable. 
Figures

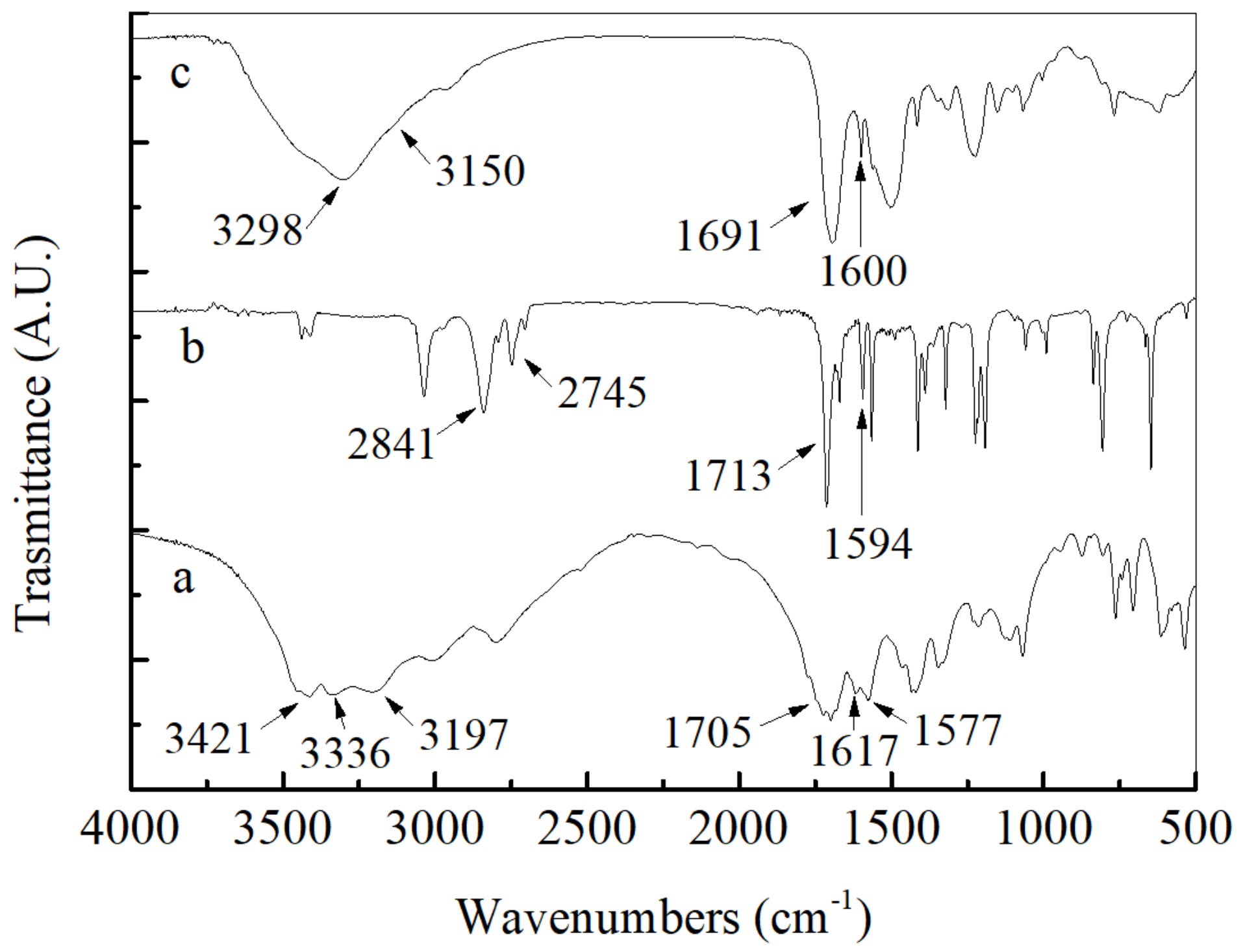

Figure 1

FTIR spectra of biuret (a), isonicotinaldehyde (b), and 6-(pyridin-4-yl)-1,3,5-triazinane-2,4-dione (c) 


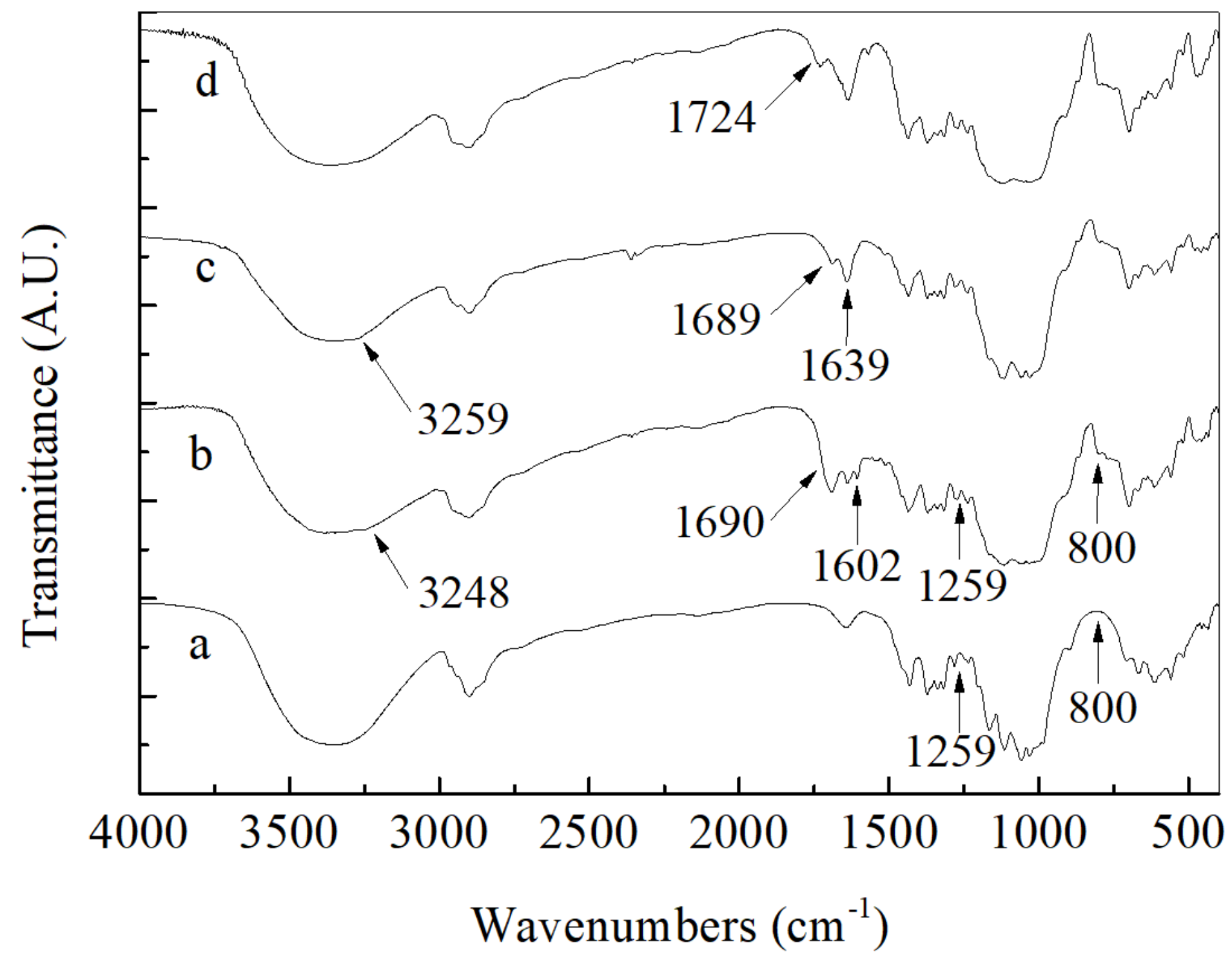

Figure 2

FTIR spectra of pristine cotton (a), silane modified cotton (b), quaternized cotton (c), and pyridinium/di-Nchloramine cotton 


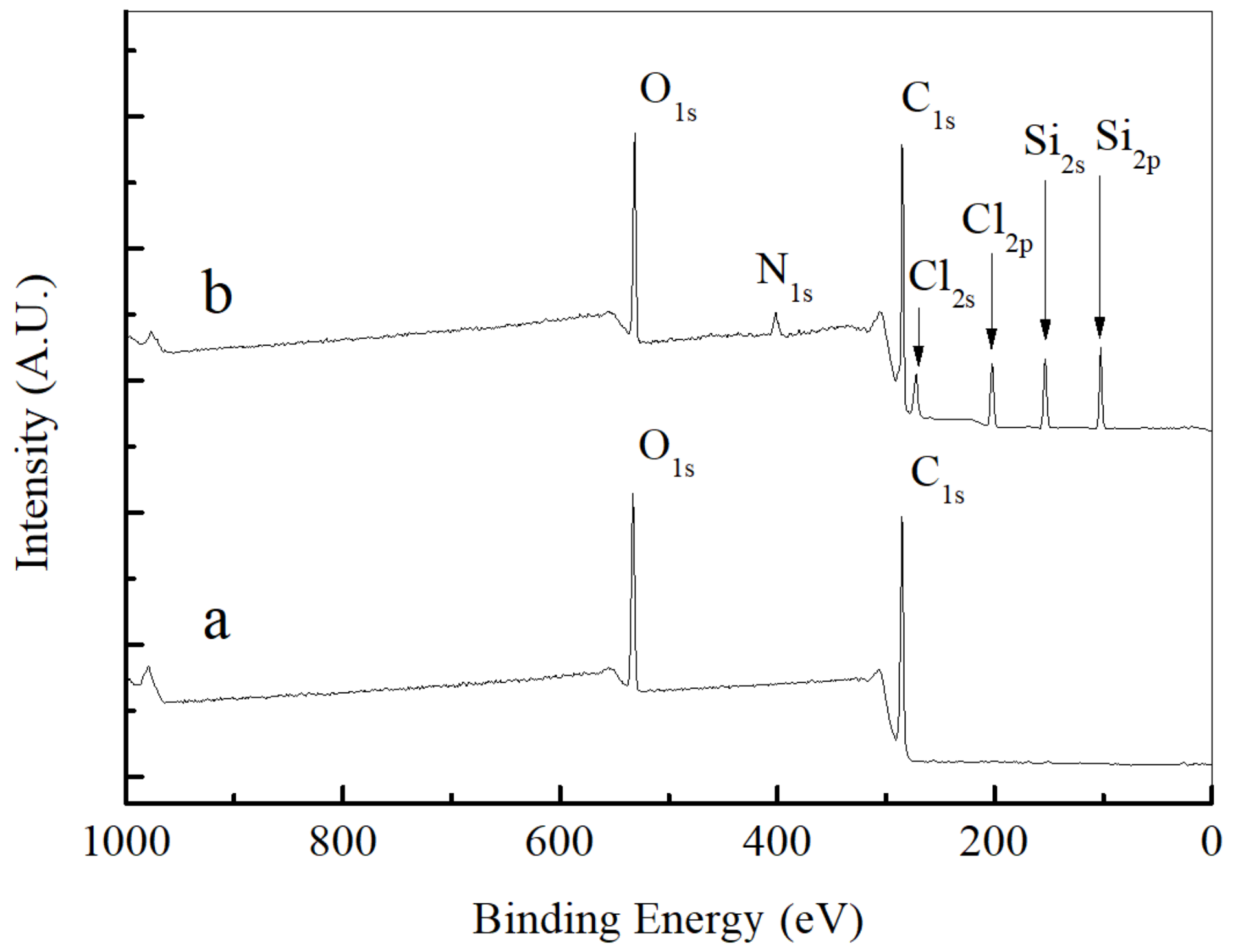

Figure 3

XPS survey scans of pure cotton (a) and pyridinium/di-N-chloramine cotton (b) 

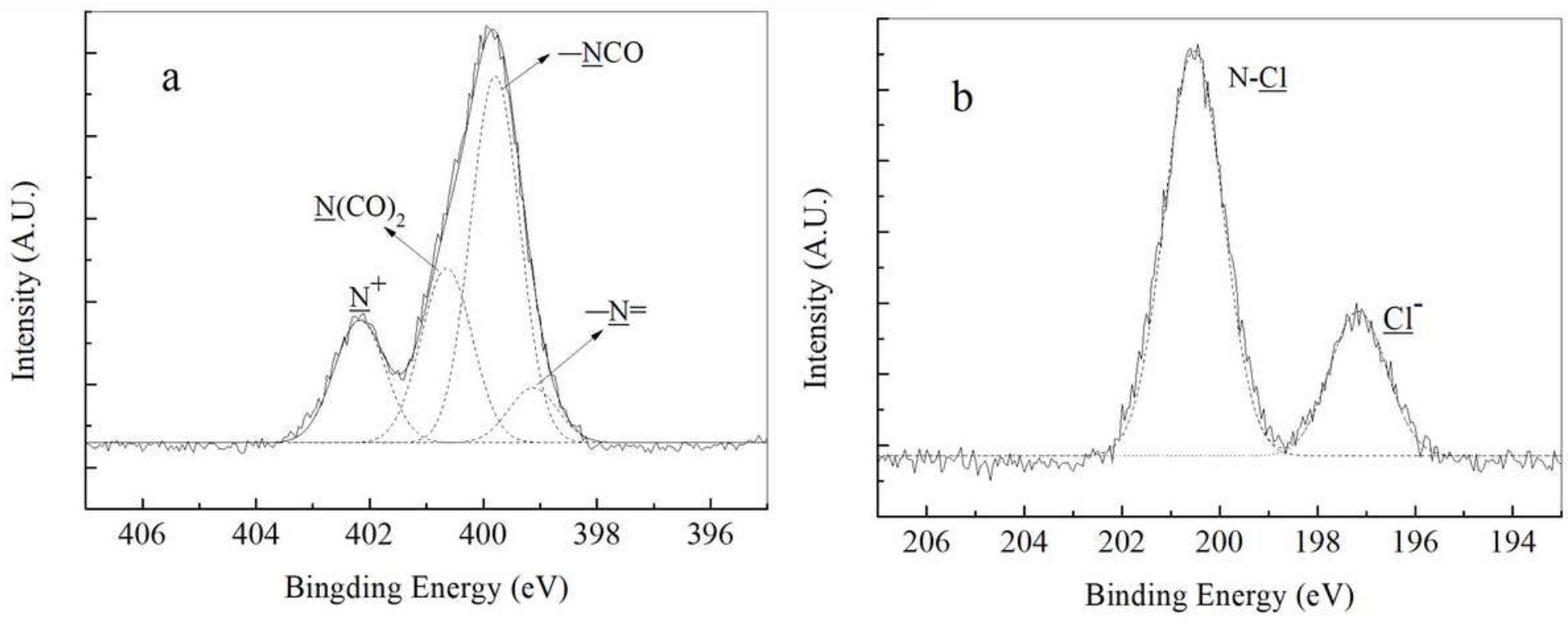

Figure 4

XPS high resolution spectra and deconvolutions of N1s (a) and Cl2p (b)

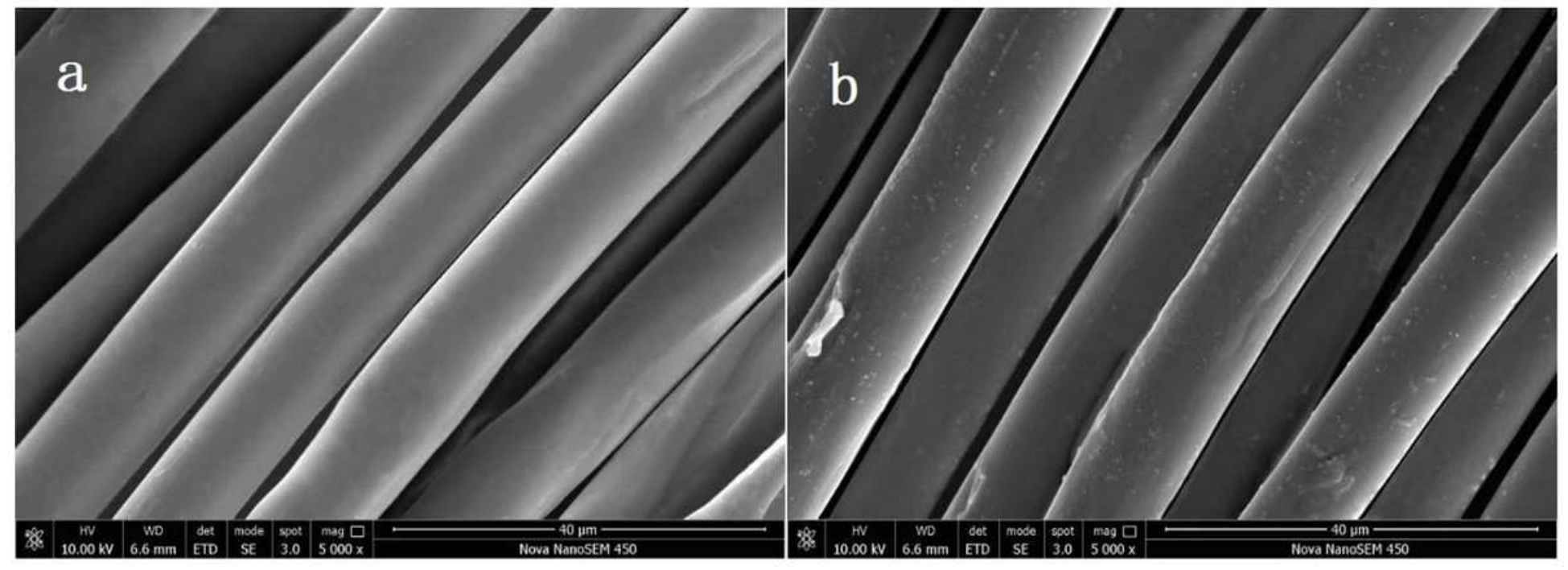

Figure 5

SEM images of pristine (a) and pyridinium/di-N-chloramine (b) cotton fibers 